\title{
PENGARUH KARAKTERISTIK BERAS TERHADAP HARGA BERAS DI KOTA TARAKAN
}

\section{THE EFFECT OF RICE CHARACTERISTICS ON RICE PRICES IN TARAKAN CITY}

\author{
Anang Sulistyo ${ }^{1)}$, Fendik Ardiansyah ${ }^{2)}$ \\ 1),2) Fakultas Pertanian, Universitas Borneo Tarakan \\ Email: ${ }^{1}$ anangtyo@borneo.ac.id
}

\begin{abstract}
ABSTRAK
Ketersediaan beras sebagai komoditas pangan yang cukup baik secara kuantitas maupun kualitas, aman, beragam, bergizi, merata dan terjangkau merupakan persyaratan penting dalam terwujudnya ketahanan pangan. Penelitian ini bertujuan untuk :1) Mengetahui mutu karakteristik beras di Kota Tarakan; 2) Mengetahui pengaruh karakteristik beras terhadap harga beras di Kota Tarakan. Penelitian ini dilaksanakan di Pasar Guser Kota Tarakan. Responden berjumlah 90 yang ditentukan dengan metode Accident Sampling.nMetode analisis yang digunakan adalah kualitatif (deskriptif) dan kuantitatif. Analisis kualitatif digunakan untuk menjelaskan karakteristik kualitas beras yang meliputi butir menir, butir patah, butir merah, butir rusak, butir mengapur, benda asing dan butir kepala. Sedangkan analisis kuantitatif menggunakan analisis regresi yang digunakan melihat pengaruh karakteristik beras terhadap harga jual beras. Hasil penelitian menunjukkan bahwa butir menir, butir merah dan butir rusak rata-rata memenuhi standar mutu SNI, sedangkan benda asing, butir patah, butir mengapur dan butir kepala rata-rata dibawah standar mutu SNI. Hasil analisis regresi menunjukkan bahwa variabel butir menir, butr merah, butir rusak, butir patah, butir mengapur dan butir kepala berpengaruh signifikan terhadap harga beras, sedangkan butir patah dan benda asing tidak berpengaruh signifikan terhadap harga beras.
\end{abstract}

\section{Kata Kunci: Beras, Harga Beras, Karakteristik Beras}

\begin{abstract}
The availability of rice as a food commodity which is sufficient both in quantity and quality, safe, diverse, nutritious, evenly distributed and affordable is an important requirement in the realization of food security. This study aims to: 1) Know the quality characteristics of rice in the City of Tarakan; 2) Knowing the effect of the characteristics of rice on the price of rice in Tarakan City. This research was conducted at the Guser Market, Tarakan City. The number of respondents was 90 who were determined by the Accident Sampling method. The methods of analysis used were qualitative (descriptive) and quantitative. Qualitative analysis is used to explain the quality characteristics of rice which include groats, broken grains, red grains, damaged grains, calcified grains, foreign objects and head grains. Meanwhile, quantitative analysis using regression analysis is used to see the effect of rice characteristics on the selling price of rice. The results showed that the average of grains, red grains and damaged grains met the SNI quality standard, while foreign objects, broken grains, calcified grains and head grains were on average below the SNI quality standard. The regression analysis showed that the variables of groats, red grains, damaged grains, broken grains, calcified grains and head grains had a significant effect on the price of rice, while broken grains and foreign objects had no significant effect on rice prices.
\end{abstract}

Keywords: Rice, Rice Price, Rice Characteristics 


\section{PENDAHULUAN}

Beras merupakan salah satu
komoditas penting dalam sendi kehidupan sosial ekonomi masyarakat Indonesia. Posisi komoditas beras bagi sebagian besar penduduk Indonesia adalah sebagai makanan pokok karena hampir seluruh penduduk Indonesia membutuhkan beras sebagai bahan makanan utamanya, disamping merupakan sumber nutrisi penting dalam struktur pangan sehingga aspek penyediaan beras menjadi hal yang sangat penting mengingat jumlah penduduk Indonesia yang kian tahun semakin meningkat.

Rasa, preferensi, keamanan dan penerimaan konsumen terhadap komoditas pangan telah banyak berubah sejak globalisasi pasar pangan (Bikram, 2013). Begitupun perubahan demografi seperti tingkat pendidikan, tingkat urbanisasi, dan tingkat partisipasi angkatan kerja wanita disertai kemajuan transportasi dan komunikasi saat ini, mempengaruhi preferensi konsumen yang lebih menekankan pada keseimbangan gizi, estetika dan mutu. Kualitas produk secara mendasar dinyatakan sebagai sifat yang lebih baik dibandingkan dengan produk yang wajar atau standarnya. Terdapat kesepakatan umum bahwa kualitas mempunyai dimensi obyektif dan dimensi subyektif. Kualitas obyektif mengacu kepada karakteristik fisik produk dan secara khusus mendapat persetujuan dari ahli, sedangkan kualitas subyektif merupakan kualitas yang dirasakan oleh konsumen (Kholiqoh, 2018)

Kualitas beras sangat ditentukan oleh karakteristiknya, terutama karakteristik fisik karena karakteristik fisiklah yang paling mudah dilihat dan paling sering diperhatikan oleh konsumen saat akan membeli beras. Karakteristik umum yang banyak mempengaruhi beras $\mathrm{di}$ pasaran antara lain kebersihan, butir rusak, butir menir, warna dan butir kepala. Perbedaan mutu dan kualitas pada beras berdampak pada perbedaan harga setiap varietas beras, beras dengan mutu premium biasanya di jual lebih mahal dipasaran karena di anggap memiliki kualitas lebih baik. Harga mempunyai fungsi sebagai petunjuk kualitas dan sebagai pengorbanan moneter. Harga dipandang sebagai konsekuensi dari kualitas, karena produk dengan kualitas yang tinggi pada umumnya mempunyai biaya produksi yang lebih tinggi dan persaingan yang ketat akan menyisihkan produk dengan harga yang tinggi namun mempunyai kualitas yang rendah. Kualitas barang yang lebih tinggi akan menurunkan risiko kegunaan sehingga meningkatkan nilai yang dirasakan oleh konsumen yang pada akhirnya meningkatkan jumlah konsumsi (Harini dkk, 2019)

Perbedaan mutu dan kualitas pada beras berdampak pada perbedaan harga setiap varietas beras, beras dengan mutu premium biasanya di jual lebih mahal dipasaran karena di anggap memiliki kualitas lebih baik. Beras dengan kualitas ini biasanya dijual dipasar modern dengan sasaran masyarakat ekonomi menengah ke atas sedangkan beras dengan kualtias medium dan kualitas rendah biasanya dapat ditemukan dipasar tradisional dengan target masyarakat ekonomi menengah ke bawah.

Berdasarkan kondisi tersebut, maka adanya penelitian atau kajian yang berhubungan dengan harga beras sangat penting dilakukan sehingga pemerintah dapat meningkatkan kesejahteraan petani melalui produksi beras dan penentuan harga secara tepat berdasarkan karakteristiknya. Adapun tujuan yang ingin dicapai dalam penelitian ini yaitu :

1. Untuk mengetahui karakteristik beras di Kota Tarakan.

2. Untuk mengetahui pengaruh karakteristik beras terhadap harga beras dikota Tarakan.

\section{METODE PENELITIAN}

Penelitian ini dilakukan di pasar Guser Kota Tarakan. Pemilihan lokasi dilakukan secara sengaja (purposive sampling) dengan pertimbangan terdapat banyak penjual yang menawarkan beras sehingga dapat diketahui variasi harga dan karakteristik beras. Metode pengambilan sampel menggunakan teknik accidental sampling, dimana 
responden dipilih secara kebetulan dengan kriteria konsumen membeli beras di pasar Guser Kota Tarakan dengan harga dari Rp. 11.000 hingga Rp. 15.000. Pada penelitian ini sampel diambil berjumlah 90 orang. Analisis data menggunakan deskriptif kualitatif dan analisis regresi berganda.

Untuk mengetahui karakteristik beras dilakukan secara manual dengan mengamati masing-masing butir beras. Penentuan tersebut dapat dilakukan dengan cara sebagai berikut:
1. Penentuan butir kapur, butir rusak dan butir merah

Amati setiap butir beras yang mengandung kapur, berwarna kuning kecoklatan, dan mengandung warna merah. Lakukan pemilihan dan pisahkan butir beras yang mengandung kapur, berwarna kuning atau rusak dan mengandung warna merah dengan pinset atau tangan. Timbang masing-masing kriteria mutu dan persentasekan terhadap beras sampel.

$$
\begin{aligned}
& \text { Persentase butir kapur }=\frac{\text { berat butir kapur }(\mathrm{g})}{\text { berat sampel }(\mathrm{g})} \times 100 \% \\
& \text { Persentase butir rusak }=\frac{\text { berat butir rusak }(\mathrm{g})}{\text { berat sampel }(\mathrm{g})} \times 100 \% \\
& \text { Persentase butir merah }=\frac{\text { berat butir merah }(\mathrm{g})}{\text { berat sampel }(\mathrm{g})} \times 100 \%
\end{aligned}
$$

2. Penentuan butir patah, butir menir dan butir kepala

Langkah-langkah yang dilakukan sebagai berikut : (a) ambil salah satu beras yang masih utuh atau tidak mengalami patah sama sekali, (b) ukur panjang dari beras utuh tersebut, (c) ukur panjang dari butir yang patah, (d) pisahkan untuk butir patah, butir menir, dan butir utuh. Jadikan butir utuh tersebut sebagai patokan. Jika butir beras berukuran kurang dari 0.25 dari butir utuh maka pisahkan menjadi butir menir. Jika panjang butir beras berukuran antara 0.25-0.75 dari beras utuh, maka golongkan butir tersebut pada butir patah. Jika panjang butir lebih dari 0.75 dari butir utuh, maka golongkan butir tersebut pada butir kepala, (e) timbang dan persentasekan masingmasaing butir tersebut dengan cara sebagai berikut.

$$
\begin{aligned}
\text { Persentase butir menir }= & \frac{\text { berat butir menir }(\mathrm{g})}{\text { berat sampel }(\mathrm{g})} \times 100 \% \\
\text { Persentase butir patah }= & \frac{\text { berat butir patah }(\mathrm{g})}{\text { berat sampel }(\mathrm{g})} \times 100 \% \\
\text { Persentase butir kepala } & =\frac{\text { berat butir kepala }(\mathrm{g})}{\text { berat sampel }(\mathrm{g})} \times 100 \%
\end{aligned}
$$

Sedangkan untuk mengetahui pengaruh karakteristik beras terhadap harga beras digunakan analisis regresi

berganda yang dapat diketahui melalui persamaan berikut:

$$
P_{r}=\alpha+\beta_{1} x_{1 r}+\beta_{2} x_{2 r}+\cdots+\beta_{7} x_{7 r}+\varepsilon
$$

Dimana $P_{r}$ adalah harga beras yang diamati, $\varepsilon$ adalah kesalahan stokastik, $x_{i r}$ adalah variabel bebas yang menjelaskan variasi karakteristik beras dan $\beta_{i r}$ adalah nilai implisit karakteristik beras. Secara terperinci persamaan regresi dijelaskan sebagai berikut:

$$
\mathrm{P}_{\mathrm{r}} \quad=\text { Harga beras }(\mathrm{Rp} / \mathrm{kg})
$$

$$
\begin{array}{ll}
X_{1} & =\text { butir menir }(\%) \\
X_{2} & =\text { butir patah }(\%) \\
X_{3} & =\text { benda asing }(\%) \\
X_{4} & =\text { butir mengapur }(\%) \\
X_{5} & =\text { butir merah }(\%) \\
X_{6} & =\text { butir rusak }(\%) \\
X_{7} & =\text { butir kepala }(\%)
\end{array}
$$




\section{HASIL DAN PEMBAHASAN}

\section{Karakteristik Mutu Beras}

Hasil penelitian menunjukkan bahwa rata-rata persentase kandungan butir menir $(1,83 \%)$, butir merah $(0,22 \%)$ dan butir rusak $(1,15 \%)$ telah memenuhi persyaratan mutu beras medium. Sedangkan butir patah $(21,51 \%)$, benda asing $(1,22 \%)$, butir mengapur $(5,10 \%)$ dan butir kepala $(78,40 \%)$ belum memenuhi persyaratan mutu beras medium standar SNI.

Tabel 1. Hasil Analisis Mutu berdasar SNI

\begin{tabular}{|l|c|c|}
\hline Karakteristik Fisik (\%) & Rata-Rata & Nilai SNI (Medium) \\
\hline Butir menir & 1.83 & 2 \\
\hline Butir patah & 21.51 & 20 \\
\hline Benda asing & 1.22 & 0,02 \\
\hline Butir mengapur & 5.10 & 2 \\
\hline Butir merah & 0.22 & 2 \\
\hline Butir rusak & 1.15 & 2 \\
\hline Butir kepala & 78.40 & 78 \\
\hline
\end{tabular}

\section{Pengaruh Karakteristik terhadap Harga Beras}

Berdasarkan hasil analisis regresi diketahui bahwa nilai R-square sebesar 0.942. hal ini menunjukkan bahwa variasi harga beras dapat dijelaskan oleh variasi variabel bebas sebesar $94 \%$, sedang $6 \%$ dijelaskan oleh varibel lain diluar model.

Tabel 2. Hasil Analisis Regresi

\begin{tabular}{lrr}
\hline \multicolumn{1}{c}{ Variabel } & Koefisien Regresi & Prob. \\
\hline Konstanta & 10859,008 & \\
Butir menir (X1) & $-452,961$ & 0,000 \\
Butir patah (X2) & 13,624 & 0,316 \\
Benda asing (X3) & 175,257 & 0,550 \\
Butir mengapur (X4) & $-138,549$ & 0,010 \\
Butir merah (X5) & $-595,930$ & 0,023 \\
Butir rusak (X6) & $-137,025$ & 0,000 \\
Butir kepala (X7) & 57,920 & 0,000 \\
\hline R square & 0,942 & 0,000 \\
\hline F-test & 164,907 & 0,000 \\
\hline
\end{tabular}

Berdasarkan analisis menghasilkan model persamaan sebagai berikut:

$Y=10859,008-452,961 X_{1}+13,624 X_{2}$

$$
\begin{aligned}
& +175,257 X_{3}-138,549 X_{4} \\
& -595,930 X_{5}-137,025 X_{6} \\
& +57,920 X_{7}+\varepsilon
\end{aligned}
$$

Nilai konstanta sebesar 10859,008 hal ini berarti jika variabel-variabel bebas bernilai 0 , maka harga beras sebesar Rp. 10.859,008. Secara simultan, variabel penjelas berpengaruh signifikan terhadap harga beras. Sedangkan Pengaruh masing-masing karakateristik beras terhadap harga beras sebagai berikut:

1. Butir Menir

Variabel butir menir berpengaruh signifikan terhadap harga beras di
Kota Tarakan dimana probabilitas $p=0,000<0,05$ pada taraf kepercayaan $95 \%$ uji dua arah. Besarnya pengaruh tersebut ditunjukkan pada nilai koefisien regresi $-452,961$, hal ini mengartikan bahwa apabila butir menir mengalami kenaikan 1 persen, maka harga beras akan mengalami penurunan sebesar Rp. 452,961.

2. Butir Patah

Variabel butir menir tidak berpengaruh signifikan terhadap harga beras di Kota Tarakan dimana probabilitas $p=0,316>0,05$ pada taraf kepercayaan $95 \%$ uji dua arah. Nilai koefisien regresi sebesar 13,624 , hal ini mengartikan bahwa apabila butir 
patah mengalami kenaikan 1 persen, maka harga beras akan mengalami kecenderungan kenaikan sebesar Rp. 13,624 . Hal ini juga dapat diartikan bahwa pada saat membeli beras, masyarakat memiliki kecenderungan tidak memperhatikan keberadaan butir patah.

3. Benda Asing

Variabel benda asing tidak berpengaruh signifikan terhadap harga beras di Kota Tarakan dimana probabilitas $p=0,550>0,05$ pada taraf kepercayaan $95 \%$ uji dua arah. Nilai koefisien regresi sebesar 175,257 , hal ini mengartikan bahwa apabila benda asing mengalami kenaikan 1 persen, maka harga beras akan mengalami kecenderungan kenaikan sebesar Rp. 175,257 . Hal ini juga dapat diartikan bahwa pada saat membeli beras, masyarakat memiliki kecenderungan tidak memperhatikan keberadaan benda asing.

4. Butir Mengapur

$\begin{array}{ccc}\text { Variabel butir } & \text { mengapur } \\ \text { berpengaruh signifikan terhadap }\end{array}$ harga beras di Kota Tarakan dimana probabilitas $p=0,010<0,05$ pada taraf kepercayaan $95 \%$ uji dua arah. Nilai koefisien regresi sebesar -138,549, hal ini mengartikan bahwa apabila butir mengapur mengalami kenaikan 1 persen, maka harga beras akan mengalami penurunan sebesar Rp. 138,549 .

5. Butir Merah

Variabel butir merah berpengaruh signifikan terhadap harga beras di Kota Tarakan dimana probabilitas $p=0,023<0,05$ pada taraf kepercayaan $95 \%$ uji dua arah. Nilai koefisien regresi sebesar -595,930, hal ini mengartikan bahwa apabila butir merah mengalami kenaikan 1 persen, maka harga beras akan mengalami penurunan sebesar Rp. 595,930 .

6. Butir Rusak

Variabel butir rusak berpengaruh signifikan terhadap harga beras di Kota Tarakan dimana probabilitas $p=0,00<0,05$ pada taraf kepercayaan $95 \%$ uji dua arah. Nilai koefisien regresi sebesar $-137,025$, hal ini mengartikan bahwa apabila butir rusak mengalami kenaikan 1 persen, maka harga beras akan mengalami penurunan sebesar Rp. 137,025.

7. Butir Kepala

Variabel butir kepala berpengaruh signifikan terhadap harga beras di Kota Tarakan dimana probabilitas $p=0,00<0,05$ pada taraf kepercayaan $95 \%$ uji dua arah. Nilai koefisien regresi sebesar 57,920, hal ini mengartikan bahwa apabila butir patah mengalami kenaikan 1 persen, maka harga beras akan mengalami kenaikan sebesar Rp. 57,920.

\section{KESIMPULAN}

Berdasarkan hasil penelitian dan analisis yang telah dilakukan, maka diperoleh kesimpulan sebagai berikut:

1. Bahwa butir menir, butir merah dan butir rusak rata-rata memenuhi standar mutu SNI, sedangkan benda asing, butir patah, butir mengapur dan butir kepala rata-rata dibawah standar mutu SNI.

2. Bahwa variabel butir menir, butir merah, butir rusak, butir patah, butir mengapur dan butir kepala berpengaruh signifikan terhadap harga beras, sedangkan butir patah dan benda asing tidak berpengaruh signifikan terhadap harga beras.

\section{DAFTAR PUSTAKA}

Badan Pusat Statistik.2020. Kalimantan Utara dalam Angka. Bulungan. BPS Kalimantan Utara.

Bikram, G.2013. A Hedonic Pricing Model of Rice for Bhutan. International Journal of Humanities and Management Sciences (IJHMS) Volume 1, Issue 2 (2013) ISSN 2320-4044 (Online).

Harini, R., Ariani, R.D., dan Supriyati.2019. Analisis Luas Lahan Pertanian Terhadap Produksi Padi Di Kalimantan Utara. Jurnal Kawistara, Vol. 9, No. 1, 22 April 2019: 15-27.

Kholiqoh,L.,2018. Analisis Pengaruh Karakteristik Fisik Beras Terhadap Harga Beras. Institut Pertanian Bogor, Bogor. 
JURNAL BORNEO SAINTEK

Volume 4, Nomor 1, April 2021

e-ISSN 2599-3313

P-ISSN 2615-434X

Lancaster, K.J.1966. A New Approach to Consumer Theory. The Journal of Political Economy, Vol.74, No.2. pp .132-157.

Roscoe, J. T. (1975). Fundamental research statistics for the behavioural sciences.(2nd ed.) New York: Holt Rinehart \& Winston.

Rosen, S.1974. Hedonic Prices and Implicit Markets: Product Differentiation in Pure Competition. The Journal of Political Economy, Vol. 82, No.1. pp. 34-55.
Available online at www.jurnal.borneo.ac.id Halaman 31-36

Unnevehr,L., \& Duff, B., \& Juliano, BO.1992. Consumer Demand for Rice Grain Quality. International Rice Research Institute, Manila Philippines and International Development Research Center, Ottawa, Canada (1992).

Widodo. 2013. Analisis Fungsi Harga Hedonik dan Permintaan Konsumen Terhadap Beras Organik Di Provinsi Jawa Tengah. [Disertasi]. Universitas Gadjah Mada. Yogyakarta. [Indonesia]. 